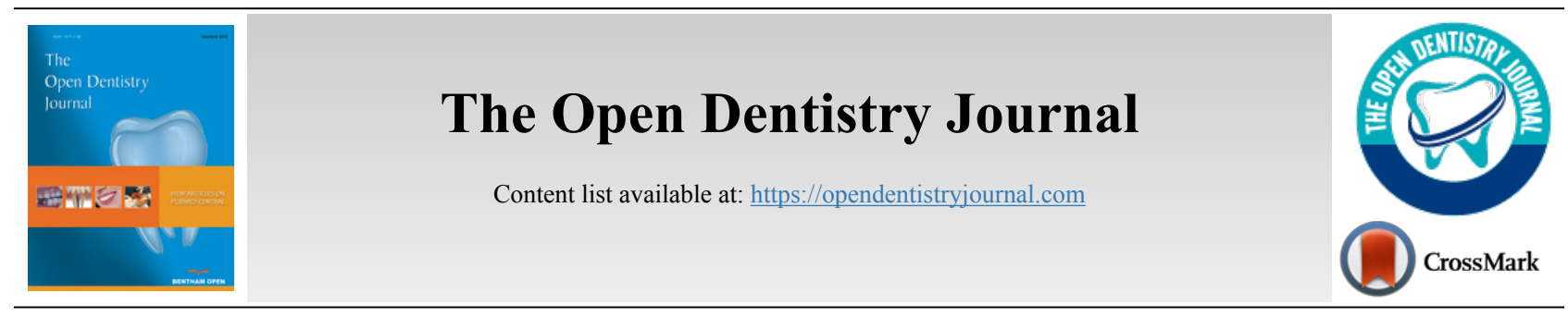

RESEARCH ARTICLE

\title{
Wind Instrumentalist Embouchure and the Applied Forces on the Perioral Structures
}

\author{
Miguel P. Clemente ${ }^{1, *}$, André Moreira ${ }^{1}$, Joaquim Mendes $^{2}$, Afonso P. Ferreira ${ }^{3}$ and José M. Amarante ${ }^{4}$ \\ ${ }^{1}$ Faculty of Dental Medicine, University of Porto, Porto, Portugal \\ ${ }^{2}$ INEGI, Labiomep, Faculty of Engineering, University of Porto, Porto, Portugal \\ ${ }^{3}$ Department of Orthodontics, Faculty of Dental Medicine, University of Porto, Porto, Portugal \\ ${ }^{4}$ Department of Surgery, Faculty of Medicine, University of Porto, Porto, Portugal
}

\begin{abstract}
:
Introduction:

The wind instrumentalist embouchure is probably one of the most demanding tasks that occurs during their musical performance. It is important to quantify the forces that are applied during the wind instrumentalist embouchure on the perioral structures.

Objective:

Quantify the force on the perioral structures involved during the embouchure mechanism of wind instrumentalists.

Methods:

Piezoresistive sensors of FlexiForce ${ }^{\mathrm{TM}}$ were placed on the mouthpiece of 28 different wind instrumentalists, in order to obtain the applied forces transmitted to the upper lip or the lower lip. The application of the sensors were done according to the particular characteristics of the different types of wind instruments, single reed, double reed or metal. Each participant performed three times three different notes at different pitches: high, medium and low. The average medium and maximum pressure was obtained from the nine essays. The sensors were connected to a data acquisition board from National Instruments and the results displayed in LabVIEW 2011.
\end{abstract}

Results:

Measurement values were obtained for the different groups of wind instruments. In an ascending order, the pressures registered where for the bassoon $(6 \mathrm{~g}-31 \mathrm{~g})$, the oboe $(17 \mathrm{~g}-125 \mathrm{~g})$, the saxophone $(39 \mathrm{~g}-120 \mathrm{~g})$, the clarinet $(54 \mathrm{~g}-106 \mathrm{~g})$, the trumpet, $(63 \mathrm{~g}-172 \mathrm{~g})$, the bisel flute $(73 \mathrm{~g}-245 \mathrm{~g})$, the French horn $(56 \mathrm{~g}-305 \mathrm{~g})$, the transversal flute $(220 \mathrm{~g}-305 \mathrm{~g})$ and the trombone $(201 \mathrm{~g}-325 \mathrm{~g})$.

\section{Conclusion:}

Metal instrumentalists seem to apply greater forces than woodwind musicians when performing the embouchure mechanism, being in this specific case the trombone the instrument from the metal group to exert more force, while on the contrary, the bassoon registered the lower values.

Keywords: Embouchure, Piezoresistive sensors, Perioral pressure, Wind instrumentalists, Dentistry, Musculoskeletal system.

\begin{tabular}{|c|c|c|c|}
\hline Article History & Received: November 30, 2018 & Revised: January 14, 2019 & Accepted: February 09, 2019 \\
\hline
\end{tabular}

\section{INTRODUCTION}

Performing arts medicine is a sub-speciality that is oriented to treat musicians, ballet dancers, actors and other people that are dedicated to performing arts. The "maladies of musicians" are reported in several researches, where the pathologies that

\footnotetext{
* Address correspondence to this author at the Faculty of Dental Medicine, University of Porto, Rua Caldas Xavier 38-1 ${ }^{\circ}$ esq, 4150-162 Porto, Portugal; Tel: +351967044 018; Fax: +351225081 445;

E-mail: miguelpaisclemente@hotmail.com
}

are described and addressed concern the musculoskeletal system [1 - 3]. Stress and anxiety can be associated to psychological aspects that a musician is exposed due to his intense daily routine and environment $[4,5]$. Apart from these health issues that are known and identified, the oral health of a musician has been "neglected" to a certain extent. There are few studies in this particular area, which is so important and vital for a wind instrumentist in order to perform correctly his/her embouchure [6 - 8]. 
The wind instrumentalist embouchure is probably one of the most demanding task that occurs during his musical performance. The embouchure technique is developed and learned since the age a wind instrumentalist chooses his/her main musical instrument, which usually can occur when they reach the age of seven or eight years old.

The Cranio-Cervical-Mandibular Complex (CCMC), that is composed by different anatomical structures such as bones, where it can be highlight the maxilla and mandible, teeth, ligaments, muscles, blood vessels, central nervous system, articulations and glands play an important role on the wind instrumentalist embouchure. The sound quality obtained as the final outcome of the musician's performance is directly proportional to the musicians grip of the embouchure, to the stabilization of the mouthpiece within the lips, teeth or both, the absence of orofacial pain, the resistance of the masticatory muscles to fatigue and even the coordinated movement between the temporomandibular joints in order to allow a correct kinematic of the mandible during the achievement of different pitches were the quantity of mouth opening, mandible protrusion or retrusion is associated to the wind instrumentalist embouchure.

Nevertheless, and from a clinical point of view, besides implementing studies with questionnaires and clinical examinations of wind instrumentalists, it is important to quantify the forces that are applied during the wind instrumentalist embouchure on the perioral structures. This contribution is fundamental to differentiate the forces that can be applied on the upper central incisors when playing a clarinet or a saxophone even if they are both single reed instruments, or the forces exerted by different brass instruments like a trumpet or/and a tuba. From an empirical point of view of a musician technical approach, there is a genera-lized knowledge that when a wind instrumentalist is playing a high note there is a higher force applied on the perioral structures comparing to a low note where a lower force can be expected. But nowadays with the advance of technology, there can be a special contribution of bioengineering, with specific software that can be implemented on the screening and acquisition of information regarding the applied forces on the perioral structures during the wind instrumentalist embouchure.

\section{AIM}

The objective of this research was to apply piezoresistive sensors on the interface between the perioral structures and the mouthpiece of single reed, double reed and brass instrument players and quantify the applied forces during their embouchure.

\section{MATERIALS AND METHODS}

\subsection{Study Population}

Twenty-eight subjects were selected from the high school of music, where they were taking there master of science degree in music performance. From the 28 wind instrumentalists, two groups were formed, wood instruments and metal instruments. The metal group was composed by 6 trumpets, 1 French horn and 1 trombone. The wood group was composed by 7 saxophonists, 7 clarinets, 4 bassoons and 2 oboes. The participants were included in this study with the following criteria: They were absent of pain in the orofacial structures, namely the lower lip and had no previous orthodontic treatment done.

\subsection{Implementation of Piezoresistive Sensors to Charac- terize Embouchure Forces}

In order to understand the forces that were applied in these wind instrumentalists during their embouchure, the piezoresistive sensors were applied on the upper and lower part of the mouthpiece. For single reed instruments (saxophone and clarinet), 2 piezoresistive sensors were placed in the upper part of the mouthpiece and one was placed on the lower part, once for this class of instruments the purpose was to measure and quantify the forces applied at the level of both maxillary central incisors and at the level of the lower lip (Fig. 1). For double reed instruments (bassoon and oboe) (Fig. 2), two piezoresistive sensors were placed on the mouthpiece to obtain the values for the upper and lower lip that are doing a labioversion during the musical performance to stabilize the mouthpiece. The major difference on the acquisition of the applied forces between these double reed instrument players and brass instruments (for the French horn, trumpets and trombone (Fig. 3) is regarding to the position where the piezoresistive sensors were applied, since the pressure exerted by the lips of the double reed instruments is done with the lips folded inside

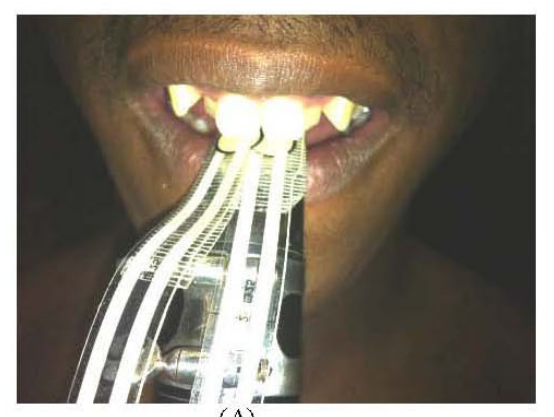

(A)

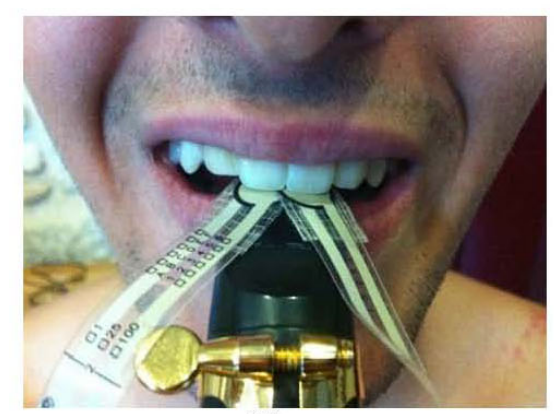

(B)

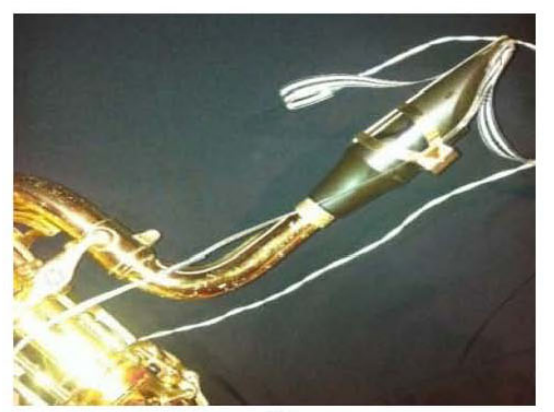

(C)

Fig. (1). (a) Piezoresistive sensors placed on the mouthpiece of the clarinet (b) and saxophone, (c) a saxophone with 2 piezoresistive sensors at the upper part and 1 piezoresistive sensor at the lower part of the mouthpiece. 


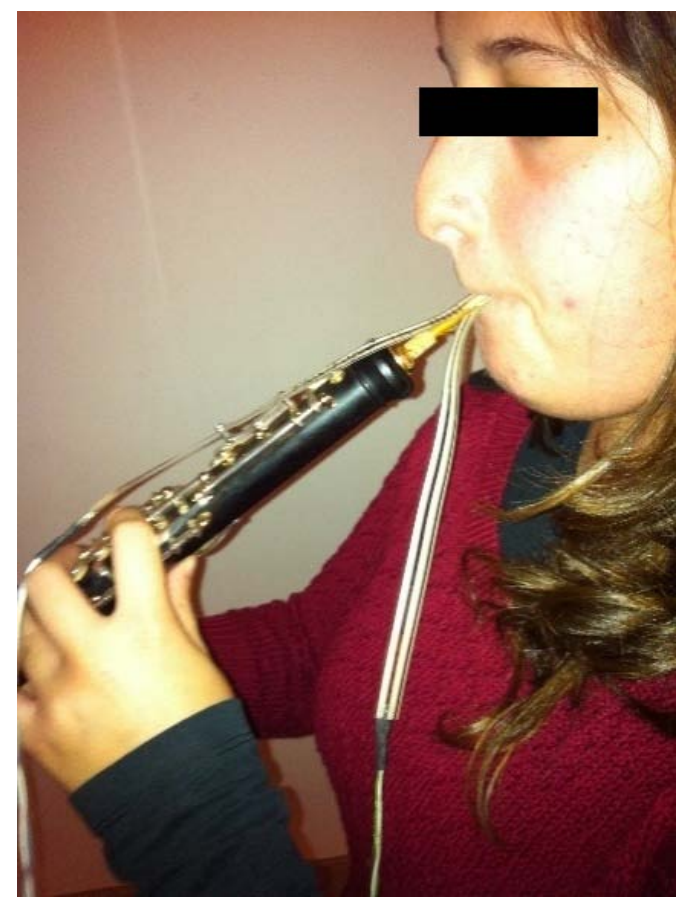

Fig. (2). Acquisition of the signal resulted from the pressure applied during an oboe's embouchure.

the oral cavity, while in the case of the brass instruments this pressure is measured on the external zone of the lips, or even on the surrounding tissues in the case of the tuba, due to the size of the mouthpiece. For the transverse flute and the bisel flute, only on the lower part of the mouthpiece one piezoresistive sensor was placed (Fig. 3). The embouchure force measurements were made with a piezoresistive sensor of FlexiForce $^{\mathrm{TM}}$, Tekscan, Boston, USA, $0.07 \mathrm{kgf} / \mathrm{cm}^{2}$. The sensor was previously calibrated and integrated according with the manufac-tures' recommendations. For calibration purposes, four different weights $(100 \mathrm{~g}, 250 \mathrm{~g}, 500 \mathrm{~g}$ and $1 \mathrm{~kg})$ were placed over the piezoresistive sensor and the voltage output was observed with a LabVIEW 2011 (National Instruments, Austin, USA). Furthermore, each participant performed three times, three different notes, at different pitches: high, medium and low. The average medium and maximum pressure was obtained from the nine essays. For the data acquisition a
Phidget Interface kit $8 / 8 / 8$ was used, being connected by USB to a computer. Later data processing was performed using Microsoft Excel ${ }^{\circledR}$.

\section{RESULTS}

The values presented in the Tables 1-7 below are the result of the signal input when a pressure was applied by the orofacial structures on the piezoresistive sensors. For each measurement, 3 essays were done in different tone pitches: high, medium and low. For each participant, the tables are presenting the average of force applied at the upper part of the mouthpiece and at the lower part of the mouthpiece. For wood wind instruments the upper part of the mouthpiece had 2 sensors contacting both upper central incisors when in brass wind instruments only one sensor was applied for the upper lip (Fig. 4). All wind instruments had a piezoresistive sensor to record the pressure applied to the lower lip (Fig. 5).

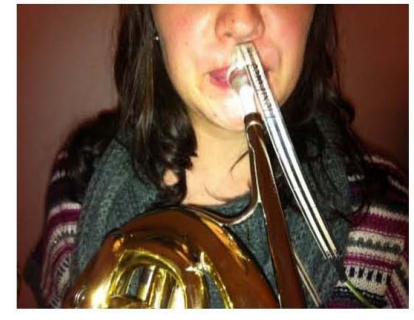

ăa瓜

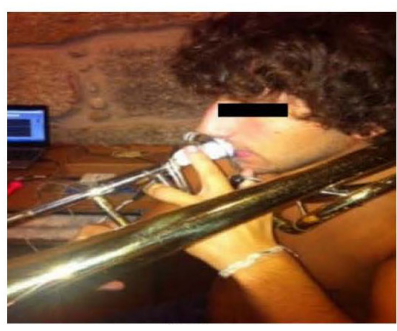

ábÆ

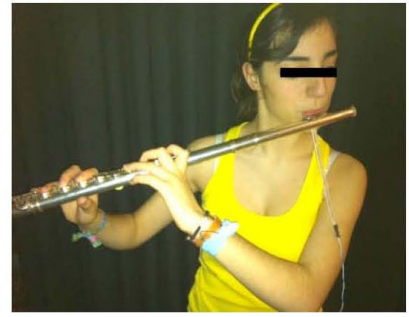

ăc屃

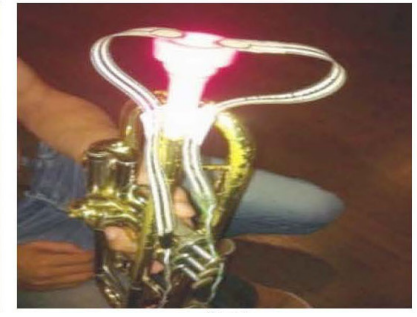

åd Ǽ

Fig. (3). a) Signal acquisition of the pressure applied during the embouchure mechanism of a French horn; b) Signal acquisition of the pressure applied during the embouchure mechanism of a trombone; c) Signal acquisition of the pressure applied during the embouchure mechanism of a transverse flute; d) Piezoresistive sensors applied to a trumpet's mouthpiece. 


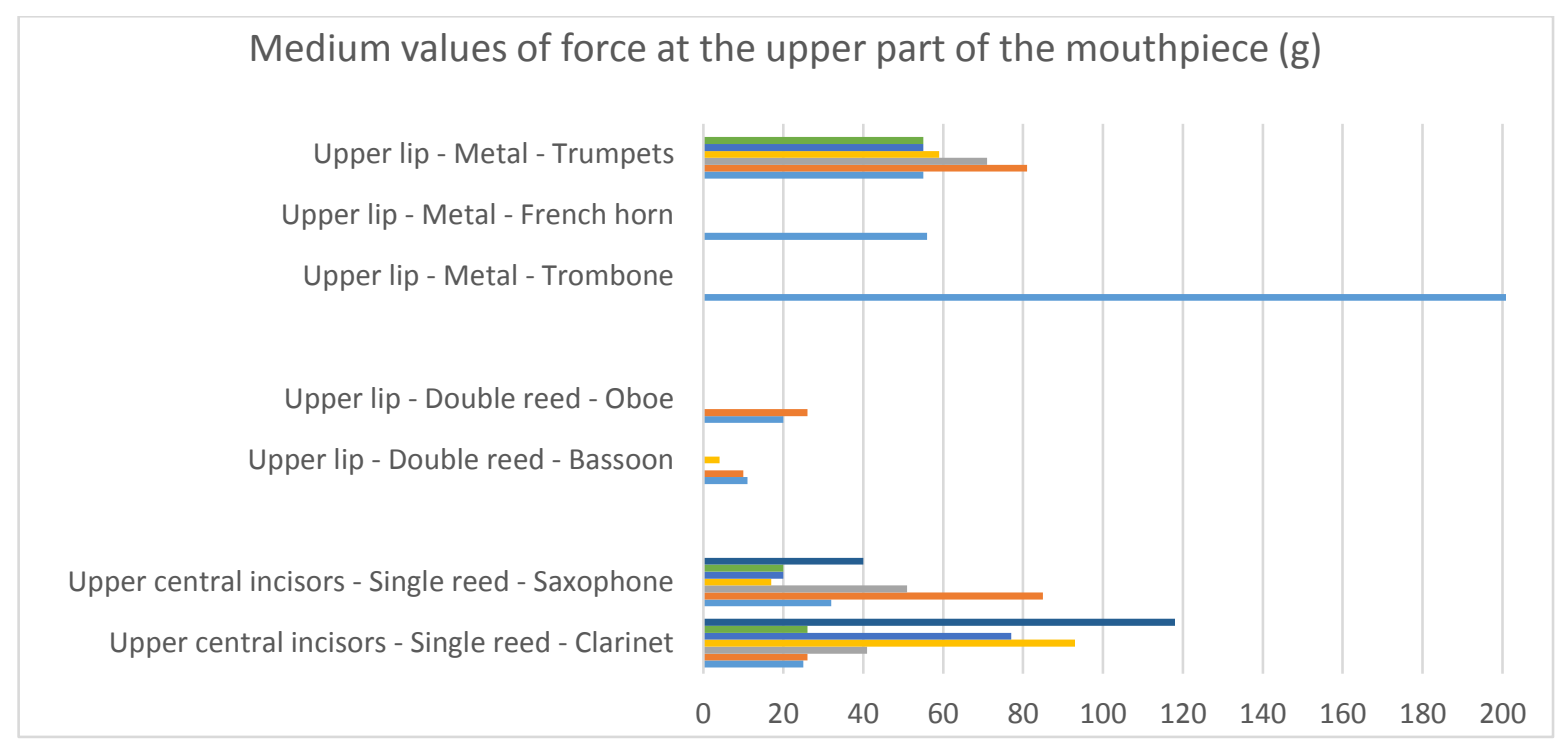

Fig. (4). Bar graph of the medium values of pressure registered at the upper part of the mouthpiece for all wind instruments.

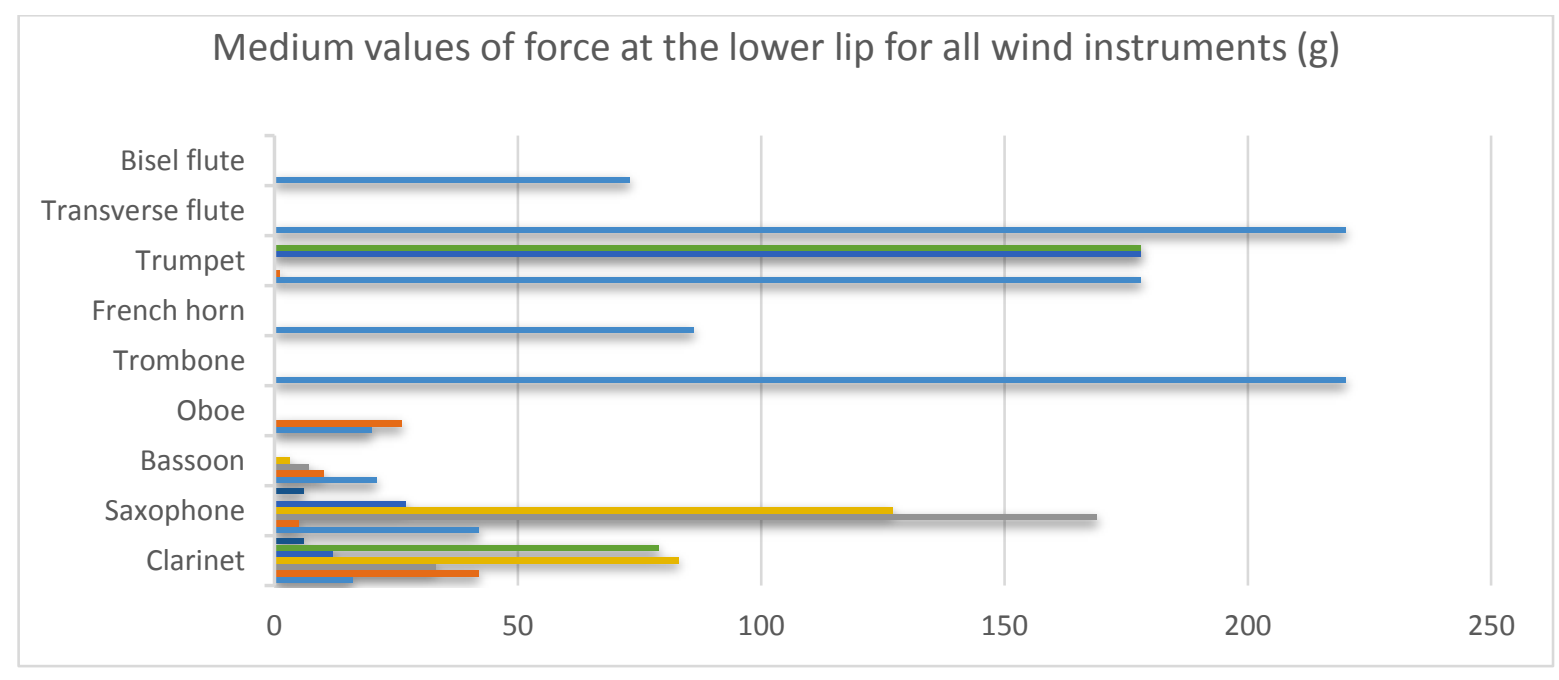

Fig. (5). Bar graph of the medium values of pressure registered at the lower lip of the mouthpiece for all wind instruments.

\section{DISCUSSION}

It is therefore important to study the human interface between the instrument and the musician. The implementation of sensors has been vital for the comprehension and development of society in many sectors of life [9, 10]. In performing arts medicine the usefulness of sensors devices is imperative since they can quantify the inherent activity of the musician that is directly linked to the biomechanics of his performance. From a medical point of view, this can provide valid information, in order to be able to fulfill a correct diagnosis and a better treatment plan when treating this specific population.
The piezoresistive sensors can quantify the differences on the applied forces on the upper and lower lip, while playing the English horn and the oboe in an orchestra musician that had a temporomandibular disorder [11]. These issues should be of major interest for dentistry since it is known that a specific applied force on a certain direction can produce tooth movement and it is known that forces over $50 \mathrm{~g}$ are capable of tipping and even moving tooth during ortho-dontic treatment [12]. The application of sensor devices like piezoresistive sensors in wind instrumentalists, can be an aid on the establishment of a prosthodontic rehabilitation and consequent treat- 
ment plan in this particular case of a saxo-phone player [13 - 17].

Relatively to the present results, the clarinets registered a higher force during the embouchure at the upper central incisors than in the lower lip. On contrary, the saxophonists showed that the greatest pressures were at the lower lip and not at the upper central incisors. The fact that the mouthpiece of these single reeds wind instruments, are different may be the answer for the opposite piezoresistive results. The clarinet has a more parallel insertion with the lingual face of the upper central incisors, turning the mouthpiece stabilization more comfortable and convenient. On the other hand, the saxophone is more parallel with the Camper plane and more perpendicular with the lower incisors resulting in a stabilization area more the lower lip and lower central incisors. For the bassoon, such as the saxophone, the greatest forces found during the embouchure mechanism were at the lower lip. Similarly, to the clarinet, the oboe showed a greater pressure being applied at the upper aspect of the mouthpiece when contacting both upper central incisors. Although, the study sample contained only 2 oboists, the forces registered clearly suggest that to perform the embouchure of this wind instrument higher forces are needed when comparing to the 4 bassoon players. From all samples, the trombone shows to be the wind instrument with the highest values of force. Moreover, for this instrument, the embouchure pressure found to be 'equally' distributed on the upper and lower lip. Regarding the French horn, the results registered suggest that it has similar values when comparing with the trumpets, once both instruments seem to demand more from the lower lip than the upper lip to produce a sound and/or perform a play. Furthermore, the trumpet players may not apply the same amount of force at the lower lip, but a higher force than the French horn instrumentalists. The only transversal flute instrumentalist had greater values of force when compared with the bisel flute instrumentalist. This finding may be related to the fact that the stabilization for a proper embouchure of the transversal flute is highly dependent on the lower lip. In this study, where it was assessed the force applied to the orofacial structures when performing the embouchure mechanism, the wind instrument that registered the greatest force was the trombone. Nevertheless, the bassoon was the type of wind instrument where less force was registered when performing the embouchure mechanism.

Table 1. Medium \& maximum values obtained from the clarinetists' group with the use of piezoresistive sensors.

\begin{tabular}{|c|c|c|c|c|c|c|}
\hline- & - & - & Minimum(g) & Maximum $(\mathbf{g})$ & Mean $(\mathbf{g})$ & STD $(\mathbf{g})$ \\
\hline \multirow{4}{*}{ Clarinet } & \multirow{3}{*}{ Upper sensor } & Medium values & 25 & 118 & 58.0 & 37.9 \\
\cline { 3 - 8 } & & Maximum values & 37 & 323 & 106.0 & 100.4 \\
\cline { 2 - 8 } & \multirow{2}{*}{ Lower sensor } & Medium values & 6 & 120 & 54.1 & 41.1 \\
\cline { 3 - 8 } & & Maximum values & 17 & 226 & 83.6 & 72.9 \\
\hline
\end{tabular}

Table 2. Medium and maximum values obtained from the saxophonists' group with the use of piezoresistive sensors.

\begin{tabular}{|c|c|c|c|c|c|c|}
\hline- & - & - & Minimum(g) & Maximum (g) & Mean (g) & STD (g) \\
\hline \multirow{4}{*}{ Saxophone } & \multirow{3}{*}{ Upper sensor } & Medium values & 17 & 85 & 38.9 & 23.4 \\
\cline { 3 - 8 } & & Maximum values & 43 & 16 & 82.7 & 41.1 \\
\cline { 2 - 7 } & \multirow{2}{*}{ Lower sensor } & Medium values & 5 & 169 & 62.7 & 68.8 \\
\cline { 3 - 8 } & & Maximum values & 20 & 320 & 120.3 & 122.3 \\
\hline
\end{tabular}

Table 3. Medium and maximum values obtained from the bassoonists' group with the use of piezoresistive sensors.

\begin{tabular}{|c|c|c|c|c|c|c|}
\hline- & - & - & Minimum(g) & Maximum $(\mathbf{g})$ & Mean (g) & STD (g) \\
\hline \multirow{4}{*}{ Bassoon } & \multirow{3}{*}{ Upper sensor } & Medium values & 0 & 11 & 6.3 & 5.2 \\
\cline { 3 - 8 } & & Maximum values & 1 & 37 & 22.0 & 16.5 \\
\cline { 3 - 8 } & \multirow{2}{*}{ Lower sensor } & Medium values & 3 & 21 & 10.3 & 7.7 \\
\cline { 3 - 8 } & & Maximum values & 8 & 49 & 30.3 & 19.1 \\
\hline
\end{tabular}

Table 4. Medium and maximum values obtained from the oboists' group with the use of piezoresistive sensors.

\begin{tabular}{|c|c|c|c|c|c|c|}
\hline- & - & - & Minimum(g) & Maximum $(\mathbf{g})$ & Mean (g) & STD (g) \\
\hline \multirow{4}{*}{ Oboe } & \multirow{3}{*}{ Upper sensor } & Medium values & 20 & 26 & 23.0 & 4.2 \\
\cline { 3 - 8 } & \multirow{2}{*}{ Lower sensor } & Maximum values & 55 & 195 & 125.0 & 98.9 \\
\cline { 3 - 8 } & & Medium values & 6 & 28 & 17.0 & 15.6 \\
\cline { 3 - 8 } & & Maximum values & 26 & 29 & 27.5 & 2.1 \\
\hline
\end{tabular}


Table 5. Medium and maximum values obtained from a Trombone and French horn player with the use of piezoresistive sensors.

\begin{tabular}{|c|c|c|c|}
\hline- & - & - & Force (g) \\
\hline \multirow{4}{*}{ Trombone } & \multirow{3}{*}{ Upper sensor } & Medium values & 201 \\
\cline { 2 - 4 } & & Maximum values & 325 \\
\cline { 2 - 4 } & \multirow{2}{*}{ Lower sensor } & Medium values & 220 \\
\cline { 2 - 4 } & & Maximum values & 307 \\
\hline \multirow{3}{*}{ French horn } & - & - & Force (g) \\
\cline { 2 - 4 } & \multirow{2}{*}{ Upper sensor } & Medium values & 56 \\
\cline { 2 - 4 } & & Maximum values & 86 \\
\cline { 2 - 4 } & Lower sensor & Medium values & 305 \\
\cline { 2 - 4 } & & Maximum values & 220 \\
\hline
\end{tabular}

Table 6. Medium and maximum values obtained from the trumpetists group with the use of piezoresistive sensors.

\begin{tabular}{|c|c|c|c|c|c|c|}
\hline- & - & - & Minimum(g) & Maximum (g) & Mean (g) & STD (g) \\
\hline \multirow{4}{*}{ Trumpets } & \multirow{3}{*}{ Upper sensor } & Medium values & 55 & 81 & 62.7 & 10.9 \\
\cline { 3 - 8 } & \multirow{2}{*}{ Lower sensor } & Maximum values & 87 & 201 & 130.3 & 54.2 \\
\cline { 3 - 8 } & & Medium values & 0 & 178 & 89.2 & 97.3 \\
\cline { 3 - 8 } & & Maximum values & 9 & 296 & 172.3 & 141.0 \\
\hline
\end{tabular}

Table 7. Medium and maximum values for the bisel flute and transverse flute players with the use of piezoresistive sensors.

\begin{tabular}{|c|c|c|c|}
\hline- & - & - & Force (g) \\
\hline \multirow{2}{*}{ Bisel Flute } & Lower & Medium values & 73 \\
\cline { 3 - 4 } & sensor & Maximum values & 249 \\
\hline \multirow{2}{*}{ Tranverse flute } & Lower sensor & Medium values & 220 \\
\cline { 3 - 4 } & & Maximum values \\
\hline
\end{tabular}

Analyzing tooth displacement can be a challenge, especially when applied to human subjects. There have been several studies and techniques to quantify the tooth movement, but the most common could probably be the use of an optical method called hologram interferometry and magnetic sensors [18 - 21]. One of the advantages of the magnetic sensors is that they are able to determine the location of center of resistance. As the magnitude of the force was increased the location of center of resistance moved towards the apical region. Nevertheless, from a theoretical perspective, it had been supposed that the center of resistance would be stationary independently to the force magnitude. The findings of Yoshida et al., can be useful for orthodontic treatments when providing forces for tooth movement [9].

The challenge of understanding the possible effects of undesired forces are important from a clinical point of view and should be applied to the pressures which wind instrumentalists are exposed daily. The different directions that the forces are carried out will determine diverse effects in terms of dental reposition or bone remodeling. Intrusion is frequently referred as one of the greatest risks for the occurence root resorption [22]. For this purpose, one should bear in mind that the mouthpiece of saxo-phone players can induce this intrusive mechanism towards the lower incisal block. The question is if this pressure and the amount of time which it is produced is sufficient to produce alterations to the root apex. Panoramic $\mathrm{X}$-rays should be performed in a dental routine appointment where wind instrumentalists should be screened with a special attention for the possibility of this risk to occur.

Understanding biology and physiology is fundamental to analyses the embouchure mechanism of a wind instrumentalist. The periodontal ligament has a very organized distribution of its fiber bundles to soften ordinary intrusive forces [23]. The morphologic pattern of the periodontal ligament is not prepared to efficiently neutralize lateral forces and/or inclination of the tooth inside the alveolus [23]. The application of forces for lateral movements requires moderation and control since excessive forces may induce root and bone lesions because of excessive or morphologically uncontrolled resorption of mineralized tissues [23]. In these particular cases, the pressures induced by the brass instrumentalist that are applied towards the perioral structures and which can be considered lateral forces. The area and the center of resistance or center of rotation of the tooth where the forces are applied can differ within each brass instrument since the diameter of the mouthpiece cup can differ from a small diameter in the trumpet or a bigger diameter in the trombone. In the past, Burstone, had already applied the holographic technique in order to measure tooth displacements and quantify the effects of time and force magnitude on tooth movement [18]. The results clearly showed 
that the force applied at the crown produces the center of rotation apical to the center of resistance; the longer the root, the further apical the center of rotation [18]. It was also found that the center of rotation is moving further apically with the increasing force magnitude, for a constant $\mathrm{M} / \mathrm{F}$ ratio and the same root geometry [18]. These aspects involving the root geometry when observing the wind instrumentalists are also important, independently that the central incisors usually have the same morphology. There are variations that have to be considered regarding the root length, the bone quality and also the periodontal status. All these issues can influence the final outcome of the tooth response to the undesired pressures produced during the musical performance.

As the results of our study demonstrated, the pressure can reach values up to $330 \mathrm{~g}$ when playing a trombone. These forces can be considered of heavy forces $(300 \mathrm{~g})$, while forces around $50 \mathrm{~g}$ are as light forces. Variables such as force magnitude, direction, distribution, duration, initial tooth displacement, stress, strain, and biologic changes of the periodontium must all be considered to obtain optimal tooth movement [24]. Yee et al., concluded that during an ortho-dontic treatment the application of different intensity of force would induce different reactions. An initial tooth movement would benefit from light forces and heavier forces tend to increase the rate and the amount of canine retraction but lose their advantage because of unwanted clinical side effects [24]. Thus, wind instrumentalists may be influenced by these pressures applied to the perioral structures, mainly at the mandible where the pressures are greater. Consequently, the clinician may need to follow closely their wind instrumentalists' patients regarding teeth position, dental and craniofacial relationships. Understanding the applied pressures during the embouchure mechanism of different wind instrumentalists can be important regarding the type of occlusion each musician has. Regarding the applied forces during the embouchure mechanism and its relation to orthodontic forces, these forces induced on the lower incisors during musical performance can eventually change the position of the lower incisors in relation to the mandibular plane. Nevertheless, this supposition should be confirmed with cephalometric measures of wind instrumentalists. The implementation of lingual retainers on the lower incisal teeth of young musicians can be a valid option. On the other hand, being able to predict the embouchure forces provides the dentistry field to embrace an area that had till now very few information regarding the applied forces on the perioral structures of wind instrument players. Eventually there can be a specific type of occlusion that could benefit from the applied forces, with this the authors do not pretend to say that playing a wind instrument can correct a malocclusion, but it can provide a force or a stimulus with a certain intensity during an amount of time that can eventually benefit or be harmful to the musician in relation to his particular occlusion. Orthodontists should be aware of these results and the forces that are applied during the embouchure of wind instrumen-talists. Future studies regarding the craniofacial relationships and tooth position should be done concerning wind instrumentalists to clarify if there are differences comparing other group of individuals.

\section{CONCLUSION}

The technique used in this study is a significant improvement over the previous methods, since it is non-invasive, and more accurate. Metal instrumentalists seem to apply greater forces than woodwind musicians when performing the embouchure mechanism, being in this specific case the trombone the instrument from the metal group to exert more force, while on the contrary the bassoon registered the lower values.

The results obtained with the piezoresistive sensors suggest that during the embouchure of a particular instrument, medium and/or heavy forces, similar to orthodontic forces, may exist and be transmitted to the orofacial structures.

\section{ETHICS APPROVAL AND CONSENT TO PARTICI- PATE}

Ethical approval for the study was obtained from the ethical committee of Faculty of Dental Medicine, University of Porto, Portugal and the relevant judgemenet's reference number is 880292 .

\section{HUMAN AND ANIMAL RIGHTS}

No Animals were used in this research. All human research procedures followed were in accordance with the ethical standards of the committee responsible for human. experimentation (institutional and national), and with the Helsinki Declaration of 1975, as revised in 2008 (http://www.wma.net/en/20 activities/10ethics/10helsinki/).

\section{CONSENT FOR PUBLICATION}

Informed consent was obtained from the participants prior to being enrolled in the study.

\section{FUNDING}

None.

\section{CONFLICT OF INTEREST}

The authors declare no conflict of interest, financial or otherwise.

\section{ACKNOWLEDGEMENTS}

The authors would like to acknowledge the support of FCT, Fundação para a Ciência e a Tecnologia, under the project FCT-UID/EMS/50022/2013.

\section{REFERENCES}

[1] Liu S, Hayden GF. Maladies in musicians. South Med J 2002; 95(7): 727-34.

[http://dx.doi.org/10.1097/00007611-200295070-00013] [PMID: 1214 4079]

[2] Kochem FB, Silva JG. Prevalence of playing-related musculoskeletal disorders in string players: A systematic review. J Manipulative Physiol Ther 2018; 41(6): 540-9.

[http://dx.doi.org/10.1016/j.jmpt.2018.05.001] [PMID: 30077421]

[3] van Selms MKA, Ahlberg J, Lobbezoo F, Visscher CM. Evidence based review on temporomandibular disorders among musicians. Occup Med (Lond) 2017; 67(5): 336-43.

[http://dx.doi.org/10.1093/occmed/kqx042] [PMID: 28472414]

[4] Nedelcut S, Leucuta DC, Dumitrascu DL. Lifestyle and psychosocial factors in musicians. Clujul Med 2018; 91(3): 312-6.

[PMID: 30093810]

[5] Ioannou CI, Furuya S, Altenmüller E. The impact of stress on motor 
performance in skilled musicians suffering from focal dystonia: Physiological and psychological characteristics. Neuropsychologia 2016; 85: 226-36.

[http://dx.doi.org/10.1016/j.neuropsychologia.2016.03.029] [PMID: 27033741]

[6] van der Weijden FN, Kuitert RB, Berkhout FRU, van der Weijden GA. Influence of tooth position on wind instrumentalists' performance and embouchure comfort : A systematic review. J Orofac Orthop 2018; 79(3): 205-18.

[http://dx.doi.org/10.1007/s00056-018-0128-2] [PMID: 29532091]

[7] Shafi I, Welbury R. Idiopathic radiographic apical root resorption in wind instrument players. Dent Update 2015; 42(10): 972-6. [http://dx.doi.org/10.12968/denu.2015.42.10.972] [PMID: 26856005]

[8] Rodríguez-Lozano FJ, Sáez-Yuguero MR, Bermejo-Fenoll A. Orofacial problems in musicians: A review of the literature. Med Probl Perform Art 2011; 26(3): 150-6. [PMID: 21987070]

[9] Yoshida N, Koga Y, Kobayashi K, Yamada Y, Yoneda T. A new method for qualitative and quantitative evaluation of tooth displacement under the application of orthodontic forces using magnetic sensors. Med Eng Phys 2000; 22(4): 293-300.

[http://dx.doi.org/10.1016/S1350-4533(00)00044-8] [PMID: 1101 8461]

[10] Lourenço S, Pais Clemente M, Coimbra D. Do pianists play with their teeth?. Int Symp Performance Sci 2018; pp. 1-6.

[11] Clemente M, Mendes J, Moreira A, Ferreira AP, Amarante JM. Orofacial trauma management in a wind instrument player. J Transl Sci 2018; 4(6): 1-5.

[PMID: 29657854]

[12] Ren Y, Maltha JC, Kuijpers-Jagtman AM. Optimum force magnitude for orthodontic tooth movement: a systematic literature review. Angle Orthod 2003; 73(1): 86-92.

[PMID: 12607860]

[13] Clemente M, Lourenço S, Coimbra D, Silva A, Gabriel J, Pinho J. Three-dimensional analysis of the cranio cervico mandibular complex during piano performance. Med Probl Perform Art 2014; 29(3): 150-4. [http://dx.doi.org/10.21091/mppa.2014.3031] [PMID: 25194112]

[14] Clemente M, Coimbra D, Silva A, Aguiar Branco C, Pinho JC. Application of Infrared thermal imaging in a violinist with temporomandibular disorder. Med Probl Perform Art 2015; 30(4): 251-4. [http://dx.doi.org/10.21091/mppa.2015.4044] [PMID: 26614980]
[15] Clemente MP, Mendes JG, Vardasca R, Ferreira AP, Amarante JM. Combined Acquisition Method of Image and Signal Technique (CAMIST) for assessment of temporomandibular disorders in performing arts medicine. Med Probl Perform Art 2018; 33(3): 205-12. [http://dx.doi.org/10.21091/mppa.2018.3029] [PMID: 30204827]

[16] Clemente M, Correia R, Sousa A, Gabriel J, Pinho J. Embouchure pressure in wind instrumentalists. $15^{\text {th }}$ International Conference on Experimental Mechanics 2012.

[17] Clemente M, Mendes J, Moreira A, Ferreira AP, Amarante JM. A prosthodontic treatment plan for a saxophone player: A conceptual approach. Dent J (Basel) 2018; 6(3): 33.

[http://dx.doi.org/10.3390/dj6030033] [PMID: 30021940]

[18] Pryputniewicz RJ, Burstone CJ. The effect of time and force magnitude on orthodontic tooth movement. J Dent Res 1979; 58(8): 1754-64.

[http://dx.doi.org/10.1177/00220345790580080101] [PMID: 288752]

[19] Burstone CJ, Every TW, Pryputniewicz RJ. Holographic measurement of incisor extrusion. Am J Orthod 1982; 82(1): 1-9. [http://dx.doi.org/10.1016/0002-9416(82)90540-1] [PMID: 6961773]

[20] Yamada Y, Yoshida N, Kobayashi K, Yamauchi K. An application of magnet and magnetic sensor: Measurement system for tooth movement. IEEE Trans Biomed Eng 1990; 37(10): 919-24. [http://dx.doi.org/10.1109/10.102803] [PMID: 2249863]

[21] Yoshida N, Jost-Brinkmann PG, Yamada Y. Initial tooth movement under extraoral force and considerations for controlled molar movement. Angle Orthod 1995; 65(3): 199-208. [PMID: 7639433]

[22] Carrillo R, Rossouw PE, Franco PF, Opperman LA, Buschang PH. Intrusion of multiradicular teeth and related root resorption with miniscrew implant anchorage: A radiographic evaluation. Am J Orthod Dentofacial Orthop 2007; 132(5): 647-55.

[http://dx.doi.org/10.1016/j.ajodo.2006.08.017] [PMID: 18005839]

[23] Alberto C, Laurindo F. Intrusive mechanics generates inclination forces and orthopedic stimuli with dental repositioning and simultaneous bone remodeling OR In intrusive mechanics intrusion forces are not applied, but the intrusive effect is obtained. Dental Press J Orthod 2011; 16(5): 20-9.

[24] Yee JA, Türk T, Elekdağ-Türk S, et al. Rate of tooth movement under heavy and light continuous orthodontic forces. Am J Orthod Dentofacial Orthop 2009; 136(2): 150.e1-9. discussion 150-1 [http://dx.doi.org/10.1016/j.ajodo.2008.06.027]

\section{(c) 2019 Clemente et al.}

This is an open access article distributed under the terms of the Creative Commons Attribution 4.0 International Public License (CC-BY 4.0), a copy of which is available at: (https://creativecommons.org/licenses/by/4.0/legalcode). This license permits unrestricted use, distribution, and reproduction in any medium, provided the original author and source are credited. 